\title{
A new model for deteriorating items with inflation under permissible delay in payments
}

\author{
R.P. Tripathi ${ }^{a^{*}}$ and Manoj Kumar
}

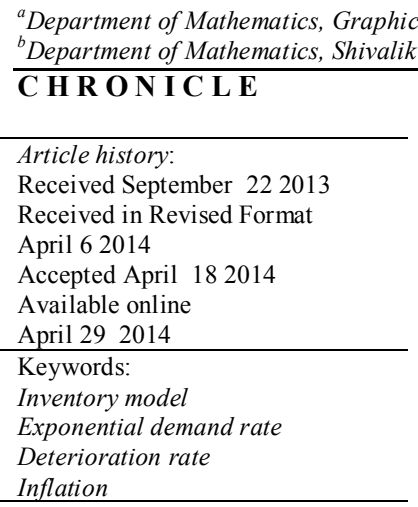

\section{Introduction}

The objective of many inventory management problems is to deal with the minimization of inventory carrying expenditures (Donalson, 1977). Thus, it is necessary to determine the optimal inventory level as well as optimal time of replenishment of inventory to meet any future demand. Among the classical inventory management models, there are many cases on solving the optimal order quantity by ignoring the type of payment. At present scenario, it is observed that supplier offers a certain fixed period to settle the account for stimulating retailers demand. During the credit period when the payment is made, some items can be sold and revenue can be accumulated to earn interest. This paper investigates inventory model for deteriorating items with exponential time dependent demand rate. In recent years, deteriorating inventory models have been widely studied. In real life situations, it is observed that demand for a particular product can be influenced by internal factor such as inflation, price and availability. The change in the demand is responsible for the change in inventory is commonly referred to as demand elasticity. Generally, inventory model considers a case in which depletion of inventory is caused by demand rate and deterioration. Most of the items deteriorate over time and this phenomena plays essential role for decision making in modern organization. During the past few decades, many researchers have developed inventory models for deteriorating items.

* Corresponding author

E-mail: tripathi_rp0231@rediffmail.com (R.P.Tripathi)

(C) 2014 Growing Science Ltd. All rights reserved.

doi: $10.5267 /$ j.ijiec.2014.4.006 
The analysis of deteriorating model is discussed by Ghare and Schrader (1963) with constant rate of deterioration. In the earlier period, researchers have discussed various demand patterns fitting the stage of product lifecycle. Resh et al. (1976) and Donaldson (1977) considered the situation and linearly time varying demand and established an algorithm to determine the optimal number of replenishments and timing. Henery (1976) further generalized the demand rate by considering a concave demand function increasing with time. Harris (1913) first introduced the basic economic order quantity (EOQ) model. Several interesting research papers are associated with deterioration, which are based on constant demand without any deterioration function (e.g. Sachan, 1984; Dave \& Patel, 1981; Goyal \& Giri, 2001; Liao \& Haung, 2010; Sana, 2010; Lin et al., 2010; Sarkar, 2012; etc.). Covert and Phillip (1973) extended Ghare and Schrader's model by considering variable rate of deterioration.

Data and Pal (1988) developed an EOQ model by introducing a variable deterioration rate and power demand pattern. Chung and Tang (1994) determined the replenishment schedules for deteriorating items with time proportional demand. However, in real life, the demand may increase or decrease in the course of time. Many researchers considered the varying demand (e.g. Sana, 2010; Sana \& Chaudhuri, 2008; Donaldson, 1977; Goyal, 1986; Kharna \& Chaudhuri, 2003; Silver \& Meal, 1969; Haringa, 1996; Goyal et al., 1986).

Various researchers have developed the inflanatory effects on the inventory policy. Liao et al. (2001) developed an inventory for initial stock dependent consumption rate when a delay in payment is permissible. Hou (2006) derived an inventory model for deteriorating items with stock dependent consumption rate and shortages under inflation and time discounting over a finite planning horizon. Buzacolt (1975) developed an inventory model with inflation. Vrat and Padmanabhan (1990) developed an inventory model under a constant inflation rate and initial stock dependent consumption rate. Datta and Pal (1991) developed a model with linear time dependent demand rate and shortages to investigate the effects of inflation with time value of money on ordering policy over a finite time horizon.

Recently, Teng et al. (2012) developed an EOQ model with trade credit financing for non-decreasing demand and fundamental theoretical results obtained. Sarkar (2011) developed an EOQ model with delay in payment for time varying deterioration rate and obtained a function for maximization of profit. Pricing and lot sizing policies for deteriorating items with partial backlogging under inflation was presented by Hsieh and Dye (2010) by considering pricing and lot sizing policies for deteriorating items with partial backlogging under inflation.

In this paper, demand rate is exponential time dependent and holding cost is time dependent. The present model is discussed by using truncated Taylor's series. The conditions for convexity of optimality are obtained and numerical examples and sensitivity analysis are given.

The rest of the paper is organized as follows: In the next section assumptions and notations are given. In section 3 mathematical formulations with maximization of total inventory cost is given. In section 4 numerical examples for the cases I and II are given. In section 5 sensitivity analysis with various parameters is given to validate the inventory cost function. Finally conclusion and future research directions are given in the last section 6.

\section{Assumptions and Notations}

The mathematical model of inventory for deteriorating items is based on the following assumptions:

(i) Demand rate is exponential and Inflation is constant

(ii) Shortages are not allowed and lead time is zero 
(iii) During the permissible delay period the sales revenue generated is deposited in an interest bearing account. At the end of the trade credit period the customer pays off all units ordered and begins paying for the interest charged on the items in stock.

(iv) There is no repair or replenishment of deteriorated items during the given cycle.

(vii) Holding cost is time dependent i.e. $h(t)=h t, \quad 0 \leq t \leq T$

The following notations are used throughout the manuscript:

\begin{tabular}{|c|c|}
\hline$h$ & : Holding cost per unit \\
\hline$p(t)=p_{0} e^{r t}$ & : Instantaneous selling price per unit \\
\hline$p_{0}$ & : Selling price per unit at $t=0$ \\
\hline C & : Purchasing price per unit at $t=0$ \\
\hline$C(t)=C_{0} e^{r t}$ & : Instantaneous ordering cost per order \\
\hline$C_{0}$ & : Ordering cost per order at $t=0$ \\
\hline$H$ & : Length of finite planning horizon \\
\hline$I_{c}$ & : Interest charged \\
\hline$I_{e}$ & : Interest earned per annum by the retailer \\
\hline$T$ & : Optimum length of cycle time \\
\hline$T_{1}$ & : Allowable delay period during settlement of the account \\
\hline$Q$ & : Optimum ordering quantity \\
\hline$r$ & : Constant rate of inflation \\
\hline$I(t)$ & : Instantaneous level of inventory \\
\hline$R=A e^{-\alpha t}$ & : Demand rate, $0<\alpha<1$ \\
\hline$A$ & : Demand at $t=0$ \\
\hline$\theta$ & : Constant deterioration rate $(\theta<\alpha)$ \\
\hline$O_{C}$ & : Ordering cost \\
\hline$C_{D}$ & : Cost of deterioration \\
\hline$I_{H C}$ & : Inventory holding cost \\
\hline$Z_{1}, Z_{2}$ & : Total cost for case 1 and 2 respectively \\
\hline
\end{tabular}

\section{Mathematical Formulation}

The level of inventory $\mathrm{I}(\mathrm{t})$ decreases gradually mainly to meet demands and due to deterioration. Thus, the variation of inventory with respect to time can be described by the following differential equation: 
$\frac{d I(t)}{d t}+\theta I(t)=-A e^{-\alpha t}, \quad 0 \leq t \leq T$

The solution of equation is given by

$I(t)=\frac{A}{\theta-\alpha}\left[e^{(\theta-\alpha) T-\theta t}-e^{-\alpha t}\right]$

and order quantity

$Q=\frac{A}{\theta-\alpha}\left[e^{(\theta-\alpha) T}-1\right]$

Since $I(t)$ is a periodic function with period $T$ hence we have $I(k T+t)=I(t)$, therefore,

$I(k T+t)=\frac{A}{\theta-\alpha}\left[e^{(\theta-\alpha) T-\theta t}-e^{-\alpha t}\right]$

Ordering Cost: Instantaneous ordering cost per order

$O_{C}=\sum_{k=0}^{n-1} C_{0} e^{k r t}=C_{0}\left(e^{r H}-1\right)\left(\frac{1}{r T}+\frac{r T}{4}-\frac{1}{2}\right)$

The number of deteriorated units $=Q-\int_{0}^{T} A e^{-\alpha t} d t$

The cost of total deteriorated units

$$
C_{D}=C\left[\frac{A}{\theta-\alpha}\left\{e^{(\theta-\alpha) T}-1\right\}+\frac{1}{\alpha}\left(e^{-\alpha T}-1\right)\right]=\frac{1}{2} A C \theta T^{2}
$$

Inventory Holding Cost $I_{H C}$ is given by

$I_{H C}=\frac{A h}{\theta-\alpha} \sum_{k=0}^{n-1} C_{0} e^{r k T} \int_{0}^{T}\left\{e^{\theta T-(\theta+\alpha) t}-e^{-\alpha t}\right\} \cdot t d t=\frac{A h C_{0}\left(e^{r H}-1\right) \theta T}{r\left(\alpha^{2}-\theta^{2}\right)}$

Depending on the customer's choice and the length of cycle time $T$ two possible cases are taken into account:

Case I $T \geq T_{1}$

Optimal cycle time $\mathrm{T}$ is greater than the permissible delay time $T_{1}$, the interest charged $\mathrm{IC}_{1}$ during the period $[0, \mathrm{H}]$ is given by

$I C_{1}=I_{c} \sum_{k=0}^{n-1} C(k T) \int_{T_{1}}^{T} I(k T+t) d t=\frac{A I_{c} C_{0}\left(e^{r H}-1\right)}{\left(\theta^{2}-\alpha^{2}\right) r} \alpha T_{1}\left(\frac{T_{1}}{T}-1\right)$

Interest earned $\mathrm{IE}_{1}$ during the period $[0, \mathrm{H}]$ is given by 
$I E_{1}=I_{e} \sum_{k=0}^{n-1} P(k T) \int_{0}^{T_{1}} A e^{-\alpha t} . t d t=P_{0} A I_{e} \frac{\left(e^{r H}-1\right)}{2 r T}\left(\frac{T_{1}^{2}}{2}-\frac{\alpha}{2} T_{1}^{3}\right)$

Total Inventory $\operatorname{Cost} Z_{1}(T)=\frac{1}{T}\left[O_{C}+C_{D}+I_{H C}+I C_{1}-I E_{1}\right]$

$=\frac{1}{T}\left[C_{0}\left(e^{r H}-1\right)\left(\frac{1}{r T}+\frac{r T}{4}-\frac{1}{2}\right)+\frac{1}{2} A C \theta T^{2}-\frac{A h C_{0}\left(e^{r H}-1\right) \theta T}{r\left(\theta^{2}-\alpha^{2}\right)}+\frac{A I_{c} C_{0}\left(e^{r H}-1\right) \alpha T_{1}\left(\frac{T_{1}}{T}-1\right)}{r\left(\theta^{2}-\alpha^{2}\right)}-\frac{P_{0} A I_{e}\left(e^{r H}-1\right)\left(\frac{T_{1}^{2}}{2}-\frac{\alpha}{2} T_{1}^{3}\right)}{r T^{2}}\right]$

Differentiating $\mathrm{Z}_{1}(\mathrm{~T})$ with respect to ' $\mathrm{T}$ ' two times we get

$$
\begin{aligned}
\frac{\partial Z_{1}}{\partial T}= & C_{0}\left(e^{r H}-1\right)\left(-\frac{2}{r T^{3}}+\frac{1}{2 T^{2}}\right)+\frac{1}{2} A C \theta+\frac{A I_{c} C_{0}\left(e^{r H}-1\right) \alpha T_{1}}{r\left(\theta^{2}-\alpha^{2}\right)}\left(-\frac{2 T_{1}}{T^{3}}+\frac{1}{T^{2}}\right) \\
& +\frac{P_{0} A I_{e}\left(e^{r H}-1\right)}{r T^{3}}\left(T_{1}^{2}-\alpha T_{1}^{3}\right) \\
\frac{\partial^{2} Z_{1}}{\partial T^{2}} & =C_{0}\left(e^{r H}-1\right)\left(\frac{6}{r T^{4}}-\frac{1}{T^{3}}\right)+\frac{A I_{c} C_{0}\left(e^{r H}-1\right) \alpha T_{1}}{r\left(\theta^{2}-\alpha^{2}\right)}\left(\frac{6 T_{1}}{T^{4}}-\frac{2}{T^{3}}\right)+\frac{3 P_{0} A I_{e}\left(e^{r H}-1\right)\left(\alpha T_{1}^{3}-T_{1}^{2}\right)}{r T^{4}}>0
\end{aligned}
$$

Optimal (minimum) solution is obtained by solving $\frac{\partial Z_{1}}{\partial T}=0$, yields

$$
\begin{aligned}
& \frac{A C \theta}{2} T^{3}+\left\{2 C_{0}\left(e^{r H}-1\right)+\frac{A C_{0} I_{c}\left(e^{r H}-1\right) \alpha T_{1}}{\left(\theta^{2}-\alpha^{2}\right)}\right\} T+\frac{P_{0} A I_{e}\left(e^{r H}-1\right)\left(T_{1}^{2}-\alpha T_{1}^{3}\right)}{r} \\
& -\frac{2 C_{0}\left(e^{r H}-1\right)}{r}-\frac{2 A I_{c} C_{0}\left(e^{r H}-1\right) \alpha T_{1}^{2}}{\left(\theta^{2}-\alpha^{2}\right)}=0
\end{aligned}
$$

Case II $T<T_{1}$

In this case, the retailer pays the procurement cost to the supplier prior to expiration of the delay period $T_{1}$ provided by the supplier. Hence, the interest charged $I C_{2}$ will be zero. Since cycle time $\mathrm{T}$ is less than permissible delay time $\mathrm{T}_{1}$, the interest earned $\mathrm{IE}_{2}$ during $[0, \mathrm{H}]$ is given by

$$
I E_{2}=I_{e} \sum_{k=0}^{n-1} P(k T)\left[\int_{0}^{T} t A e^{-\alpha t} d t+\left(T_{1}-T\right) \int_{0}^{T} A e^{-\alpha t} d t\right]=P_{0} I_{e} A \frac{\left(e^{r H}-1\right)}{r}\left(T_{1}-\frac{1}{2} T-\frac{1}{2} \alpha T T_{1}\right)
$$

Total Inventory Cost in this case $Z_{2}(T)=\frac{1}{T}\left[O_{C}+C_{D}+I_{H C}-I E_{2}\right]$

$$
Z_{2}=\frac{1}{T}\left[C_{0}\left(e^{r H}-1\right)\left(\frac{1}{r T}+\frac{r T}{4}-\frac{1}{2}\right)+\frac{1}{2} A C \theta T^{2}-\frac{A h C_{0}\left(e^{r H}-1\right) \theta T}{r\left(\theta^{2}-\alpha^{2}\right)}-\frac{P_{0} A I_{e}\left(e^{r H}-1\right)}{r}\left(T_{1}-\frac{1}{2} T-\frac{1}{2} \alpha T_{1} T\right)\right]
$$

Differentiating partially (16) w.r.t. ' $\mathrm{T}$ ' two times yields 


$$
\begin{aligned}
& \frac{\partial Z_{2}}{\partial T}=C_{0}\left(e^{r H}-1\right)\left(-\frac{2}{r T^{3}}+\frac{1}{2 T^{2}}\right)+\frac{1}{2} A C \theta+\frac{P_{0} A I_{e}\left(e^{r H}-1\right)}{r} \frac{T_{1}}{T^{2}} \\
& \frac{\partial^{2} Z_{2}}{\partial T^{2}}=C_{0}\left(e^{r H}-1\right)\left(\frac{6}{r T^{4}}-\frac{1}{T^{3}}\right)-\frac{2 P_{0} A I_{e}\left(e^{r H}-1\right)}{r} \frac{T_{1}}{T^{3}}>0
\end{aligned}
$$

Optimal (minimum) solution is obtained by solving $\frac{\partial Z_{2}}{\partial T}=0$, yields the following

$$
\frac{A C \theta}{2} T^{3}+\left\{\frac{C_{0}\left(e^{r H}-1\right)}{2}+\frac{P_{0} A I_{e}\left(e^{r H}-1\right)}{r} T_{1}\right\} T-\frac{2 C_{0}\left(e^{r H}-1\right)}{r}=0
$$

Note: Truncated Taylor's series in exponential terms i.e $e^{\alpha T} \approx 1+\alpha T+\frac{1}{2} \alpha^{2} T^{2}+\ldots$ etc. is used from Eqs. (5-17) for finding closed form solution.

\section{Numerical Example 1}

Let

$$
\begin{aligned}
& A=100, \quad \theta=0.01 \quad r=0.01 \text { to } 0.05, \quad \alpha=0.1, \quad H=1, \quad h=0.02, \quad C_{0}=10 \\
& I_{e}=0.12, \quad C=15, \quad I_{c}=0.15, \quad P_{0}=20, T_{1}=15,30,45,60,75 \text { and } 90 \text { days }
\end{aligned}
$$

Optimal solution for different values of parameters associated with model for $T \geq T_{1}$ is given in Table 1 as follows,

\section{Table 1}

The results of optimal solution for different values of $T>T_{1}$

\begin{tabular}{clllllll}
\hline & & \multicolumn{7}{c}{$T_{1}$ (Days) } \\
\hline$r$ & Parameters & 15 & 30 & 45 & 60 & 75 & 90 \\
\hline \multirow{3}{*}{0.01} & T(years) & 1.37847 & 1.34582 & 1.28789 & 1.19730 & 1.05657 & 0.807657 \\
& $Q$ (units) & 129.639 & 126.751 & 121.605 & 113.505 & 100.789 & 77.90000 \\
& $Z$ (\$) & 79.8319 & 122.78 & 175.643 & 209.926 & 271.264 & 353.7040 \\
\hline \multirow{3}{*}{0.02} & T(years) & 1.37967 & 1.34311 & 1.2774 & 1.17236 & 1.00147 & 0.641322 \\
& Q(units) & 130.626 & 127.347 & 121.430 & 111.906 & 96.2403 & 62.51480 \\
& Z(\$) & 80.1079 & 123.476 & 168.433 & 218.617 & 282.468 & 394.3190 \\
\hline \multirow{3}{*}{0.03} & T(years) & 1.38100 & 1.34080 & 1.26790 & 1.14934 & 0.947806 & 0.329037 \\
& Q(units) & 131.635 & 127.980 & 121.326 & 110.432 & 91.7048 & 32.52770 \\
& Z(\$) & 80.3821 & 124.153 & 170.096 & 222.682 & 294.314 & 338.4250 \\
\hline
\end{tabular}

\section{Numerical Example 2}

Let $A=100, \quad \theta=0.01, \quad r=0.01$ to $0.05, \alpha=0.1, \quad H=1, h=0.02, \quad I_{e}=0.02$, $T_{1}=225,240,255,270,285$ and 300 days

Optimal solution for different values of parameters associated with model for $T<T_{1}$ 
Table 2

The results of optimal solution for different values of $T<T_{I}$

\begin{tabular}{|c|c|c|c|c|c|c|c|}
\hline \multicolumn{8}{|c|}{$T_{l}($ Days $)$} \\
\hline$r$ & Parameters & 225 & 240 & 255 & 270 & 285 & 300 \\
\hline \multirow{3}{*}{0.01} & $T$ (years) & 0.60691 & 0.58707 & 0.56792 & 0.54947 & 0.53173 & 0.51470 \\
\hline & $Q$ (units) & 59.4199 & 57.5173 & 55.6782 & 53.9042 & 52.1960 & 50.5538 \\
\hline & Z(Dollars) & 87.6304 & 84.9451 & 82.1664 & 79.2914 & 76.3174 & 73.2419 \\
\hline \multirow{3}{*}{0.02} & $T$ (years) & 0.60680 & 0.58694 & 0.56776 & 0.54930 & 0.53154 & 0.51449 \\
\hline & $Q$ (units) & 59.4095 & 57.5042 & 55.6630 & 53.8870 & 52.1773 & 50.5340 \\
\hline & $Z$ (Dollars) & 87.9197 & 85.2203 & 82.4269 & 79.5366 & 76.5466 & 73.5443 \\
\hline \multirow{3}{*}{0.03} & $T$ (years) & 87.9197 & 85.2203 & 82.4269 & 79.5366 & 76.5466 & 73.5443 \\
\hline & $Q$ (units) & 59.3990 & 57.4911 & 55.6475 & 53.8696 & 52.1584 & 50.5138 \\
\hline & Z(Dollars) & 88.2111 & 85.4976 & 82.6894 & 79.7836 & 76.7775 & 73.6684 \\
\hline \multirow{3}{*}{0.04} & $T$ (years) & 0.60658 & 0.58666 & 0.56744 & 0.54893 & 0.53115 & 0.51407 \\
\hline & $Q$ (units) & 59.3883 & 57.4776 & 55.6318 & 53.8521 & 52.1394 & 50.4936 \\
\hline & Z(Dollars) & 88.5047 & 85.7770 & 82.9538 & 80.0324 & 77.0101 & 73.8841 \\
\hline \multirow{3}{*}{0.05} & T(years) & 0.60647 & 0.58652 & 0.56728 & 0.54875 & 0.53095 & 0.51386 \\
\hline & $Q$ (units) & 59.3774 & 57.4641 & 55.6161 & 53.8345 & 52.1202 & 50.4733 \\
\hline & Z(Dollars) & 88.8006 & 86.0584 & 83.2202 & 80.2831 & 77.2444 & 74.1014 \\
\hline
\end{tabular}

\section{Sensitivity Analysis: Case I}

When $\theta$ and $\alpha$ are allowed to vary by using $T_{1}=15,30,45,60,75$ and 90 days. We get different values of parameters as shown in Table 3 as follows,

Table 3

The results of optimal solution for different values of $\theta$

\begin{tabular}{|c|c|c|c|c|c|c|c|}
\hline \multicolumn{8}{|c|}{$\theta$} \\
\hline$\alpha$ & Parameters & 0.01 & 0.02 & 0.03 & 0.04 & 0.05 & 0.06 \\
\hline \multirow{4}{*}{0.2} & $T_{1}$ (Days) & 15 & 30 & 45 & 60 & 75 & 90 \\
\hline & $T$ (years) & 1.25623 & 0.97230 & 0.81087 & 0.68160 & 0.55175 & 0.37573 \\
\hline & $Q$ (units) & 111.756 & 89.1972 & 75.7469 & 64.5750 & 52.9536 & 36.6021 \\
\hline & $\bar{Z}$ (Dollars) & 44.8472 & 94.0812 & 146.748 & 201.516 & 254.443 & 260.742 \\
\hline \multirow{3}{*}{0.3} & $T$ (years) & 1.25676 & 0.97432 & 0.81564 & 0.69134 & 0.57162 & 0.42688 \\
\hline & $Q$ (units) & 105.320 & 85.2724 & 73.2114 & 85.0612 & 53.2657 & 40.5738 \\
\hline & Z(Dollars) & 33.9366 & 68.2219 & 103.366 & 138.058 & 169.279 & 180.020 \\
\hline \multirow{3}{*}{0.4} & $T$ (years) & 1.25704 & 0.97544 & 0.81833 & 0.69687 & 0.58266 & 0.45193 \\
\hline & $Q$ (units) & 99.3651 & 81.5068 & 70.6055 & 61.6334 & 52.7090 & 41.8925 \\
\hline & Z(Dollars) & 28.9211 & 56.3023 & 83.5749 & 109.697 & 132.318 & 141.359 \\
\hline \multirow{3}{*}{0.5} & $T$ (years) & 1.25723 & 0.97620 & 0.82023 & 0.70085 & 0.59061 & 0.46915 \\
\hline & $Q$ (units) & 93.8617 & 77.9389 & 68.0628 & 59.9099 & 51.8637 & 42.3895 \\
\hline & $\bar{Z}$ (Dollars) & 26.0511 & 49.4608 & 72.2592 & 93.6252 & 111.656 & 119.040 \\
\hline
\end{tabular}

Case II: When $\theta$ and $r$ are allowed to vary by using $\mathrm{T}_{1}=225,240,255,270,285$ and 300 days. We get different values of parameters as shown in Table 4 as follows, 
Table 4

The results of optimal solution for different values of $\theta$

\begin{tabular}{|c|c|c|c|c|c|c|c|}
\hline & & & & $\theta$ & & & \\
\hline \multirow[t]{2}{*}{$r$} & Parameters & 0.03 & 0.04 & 0.05 & 0.06 & 0.07 & 0.08 \\
\hline & $T_{1}$ (Days) & 225 & 240 & 255 & 270 & 285 & 300 \\
\hline \multirow{3}{*}{0.01} & $T$ (years) & 0.60691 & 0.56002 & 0.52335 & 0.49336 & 0.46807 & 0.44626 \\
\hline & $Q$ (units) & 59.4199 & 55.0715 & 51.6565 & 48.8530 & 46.4806 & 44.4280 \\
\hline & Z(Dollars) & 87.6304 & 118.694 & 158.066 & 213.142 & 300.834 & 471.514 \\
\hline \multirow{3}{*}{0.02} & $T$ (years) & 0.60680 & 0.55999 & 0.52336 & 0.49340 & 0.46813 & 0.44633 \\
\hline & $Q$ (units) & 59.4095 & 55.0683 & 51.6575 & 48.8565 & 46.4857 & 44.4342 \\
\hline & Z(Dollars) & 87.9107 & 119.116 & 158.665 & 214.000 & 302.115 & 473.637 \\
\hline \multirow{3}{*}{0.03} & T(years) & 0.60669 & 0.55995 & 0.52337 & 0.49344 & 0.46818 & 0.44638 \\
\hline & $Q$ (units) & 59.3990 & 55.0050 & 51.6582 & 48.8598 & 46.4906 & 44.4401 \\
\hline & Z(Dollars) & 88.2111 & 119.542 & 159.270 & 214.864 & 303.405 & 475.774 \\
\hline \multirow{3}{*}{0.04} & T(years) & 0.66658 & 0.55991 & 0.52338 & 0.49347 & 0.46823 & 0.44645 \\
\hline & $Q$ (units) & 59.3883 & 55.0614 & 51.6589 & 48.8631 & 46.4955 & 44.4461 \\
\hline & Z(Dollars) & 88.5047 & 119.971 & 159.878 & 215.734 & 304.704 & 477.925 \\
\hline \multirow{3}{*}{0.05} & $T$ (years) & 0.60647 & 0.55988 & 0.52338 & 0.49350 & 0.46827 & 0.44651 \\
\hline & $Q($ units $)$ & 59.3774 & 55.0578 & 51.6594 & 48.8662 & 46.5002 & 44.4518 \\
\hline & Z(Dollars) & 88.8006 & 120.402 & 160.322 & 216.609 & 306.011 & 480.091 \\
\hline
\end{tabular}

From the above tables we conclude the following results:

From Table 1, we observe that:

Increase in $T_{1}$ results decrease in $\mathrm{T}, \mathrm{Q}$ and increase in $\mathrm{Z}$, keeping $\theta, \alpha$ and $r$ constant and increase in $r$ results increase in $T, Q$ and $Z$ keeping $T_{l}$ constant.

From Table 2, we observe that:

Increase in $T_{1}$ results decrease in $T, Q$ and $Z$ keeping $r$ constant and increase in $r$ results increase in $T$, $Q$ and $Z$ keeping $T_{l}$ constant.

From Table 3, we observe that:

Increase in deterioration rate $\theta$ results decrease in $\mathrm{T}, \mathrm{Q}$ and increase in $\mathrm{Z}$ keeping $\alpha$ constant. An increase in $\alpha$ results increase in $\mathrm{T}$ and decrease in $\mathrm{Q}$ and $\mathrm{Z}$ keeping $\theta$ and

$T_{l}$ constant.

From Table 4, we observe that:

Increase in $\theta$ results decrease in $T, Q$ and increase in $Z$ keeping $r$ constant. An increase in $r$ results increase in $T, Q$ and $Z$.

\section{Conclusion}

In this paper, an inventory model has been developed for deteriorating items under permissible delay in payments. Optimal solutions were obtained for both cases i.e. case I and II. Numerical examples and sensitivity analysis have been presented to obtain optimal cycle time and optimal total average cost per unit time. The sensitivity analysis is quite sensitive to the managerial point of view.

The proposed model can be extended in several ways for instance we may consider the demand rate as quadratic time dependent or stock dependent patterns as well as discount demand. We could extend the 
model for non - deteriorating demand function to stock dependent demand function. In addition, we could generate the model to allow shortages, finite capacity and others.

\section{References}

Buzacott, J. A. (1975). Economics order quantities with inflation. Operational Research Quarterly, 26, $553-558$.

Covert, R.P., \& Phillip, G.C. (1973). An EOQ model with Weibull distribution deterioration. AIIE Transportations, 5, $323-326$.

Chung, K.J., \& Ting, P.S. (1994). On replenishment schedule for deteriorating items with time proportional demand. Production Planning and Control, 5(4), 392 - 396.

Dutta, T.K., \& Pal, A.K. (1991). Effects on inflation and time value of money on an inventory model with linear time - dependent rate and shortages. European Journal of Operational Research, 52, 326 $-333$.

Dave, U., \& Patel, L.K. (1981). (T, $\left.\mathrm{S}_{\mathrm{i}}\right)$ policy inventory model for deteriorating items with time proportional demand. Journal of Operation Research Society, 32, 137 -142.

Donalson, W. A. (1977). Inventory replenishment policy for a linear trend in demand. An analytical solution. Operational Research Quarterly, 28, 663 - 670.

Donaldson, W.A. (1977). Inventory replenishment policy for a linear trend in demand, an analytical solution. Operations Research Quarterly, 28, 663 - 670.

Dutta, T.K., \& Pal., A.K. (1988). Order level inventory system with power demand pattern for items with variable rate of deterioration. Indian Journal of Pure and Applied Mathematics 19, 1043 1053.

Ghare P.M., \& Schrader, S.K. (1963). A model for exponentially decaying inventory. Journal of Industrial Engineering, 14 (5), 238 - 243.

Goyal, S.K. (1986). On improving replenishment policies for real trend in demand. Eng. Cost prod. Econ. 10, $73-76$.

Goyal, S.K., Kusy, M., \& Soni, R. (1986). A note on economic order intervals for an item with linear trend demand Eng. Costs Prod. Econ. 10, 253 - 255.

Harris, F.W. (1913). How many parts to make at once. Factory Mag. Manage, 135 - 136-152.

Henery, R.J. (1976). Inventory replenishment policy for increasing demand. Journal of the Operational Research Society, 30(7), $611-617$.

Haringa, M. (1996). Optimal EOQ models for deteriorating items with time - varying demand. Journal of the Operational Research Society, 47, 1228 - 1246.

Hou, K.L. (2006). An inventory model for deteriorating items with stock dependent consumption rate and shortages under inflation and time discounting. European Journal of Operational Research, $168,463-474$.

Hsieh, T.P., \& Dye, C.Y. (2010). Pricing and lot sizing policies for deteriorating items with partial backlogging under inflation. Expert Systems with Applications, 37, $7234-7242$.

Kharna, K.S., \& Chaudhuri. (2003). A note on an order - level inventory model for a deteriorating item with time dependent quadratic demand. Computer and Operations Research, 30, 1901-1916.

Goyal, S.K., \& Giri, B.C. (2001). Recent trends in modeling of deteriorating inventory. European Journal of Operational Research. 134, 1 - 16.

Lin, J.J., \& Haung K.N. (2010). Deteriorating Inventory model deteriorating items with trade credits financing and capacity constraints. Computational and Industrial Engineering ,59, 611 - 618.

Lin, Y.H., Lin. C., \& Lin, B. (2010). On conflict and cooperation in a two - echelon inventory model for deteriorating items. Computers and Industrial Engineering, 59, $703-711$.

Liao, H.C. Tsai, C.H., \& Su, C.T. (2001). An inventory model for deteriorating items under inflation when a delay in payment is permissible. International Journal of Production Economics, 63, 207 214.

Resh, M., Friedman, M., \& Barbosa, L.C. (1976). On a general solution of the deterministic lot size problem with time - proportional demand. Operations Research 24, $718-725$. 
Sachan, R.S., (1984). On $\left(\mathrm{T}, \mathrm{S}_{\mathrm{i}}\right)$. policy inventory model for deteriorating items with time proportional demand. Journal of Operation Research Society, 35, 1013 - 1019.

Sana, S.S. (2010). Optimal selling price and lot size with varying deterioration and partial backlogging. Applied Mathematics and Computation, 217, 185 - 194.

Sarkar, B. (2011). An EOQ model with delay in payments and time varying deterioration rate. Mathematical and Computer Modeling (Article in press).

Sarkar, B. (2012). An EOQ model with delay in payments and time varying deterioration rate. Mathematical and Computer Modeling, 55, $367-377$.

Sana, S., \& Chaudhuri, K.S. (2008). A deterministic EOQ model with delays in payments and price discount offers. European Journal Operational Research, 184, 509 - 533.

Silver, E.A., \& Meal, H.C. (1969). A simple modification of the EOQ for the case of varying demand rate. Production and Inventory Management ,10, $52-65$.

Teng, J.T., Min, J., \& Pan, Q. (2012). Economic order quantity model with trade credit financing for non - decreasing demand. Omega, 40, 328 - 335.

Vrat, P., \& Padmanabhan, G. (1990). An inventory model under inflation for stock dependent consumption rate items. International Journal of Production Economics, 19, 379 - 383. 